\title{
An Empirical Investigation on Leadership Styles Applied for Global Brand Management of Multinational Organizations in the United States
}

\author{
Tilokie Depoo ${ }^{1}$, Gehan Dhameeth Shanmuganathan ${ }^{2}$ \\ ${ }^{1}$ Business School, Metropolitan College of New York, New York, USA \\ ${ }^{2}$ Business School, Wells College, Aurora, USA \\ Email: dhameeth@gmail.com
}

Received March 26, 2013; revised May 3, 2013; accepted May 17, 2013

Copyright (C) 2013 Tilokie Depoo, Gehan Dhameeth Shanmuganathan. This is an open access article distributed under the Creative Commons Attribution License, which permits unrestricted use, distribution, and reproduction in any medium, provided the original work is properly cited.

\begin{abstract}
Purpose: The purpose of this study is to understand the application of leadership styles in multinational organizations operating in the United States for their global brand management. Design/Methodology/Approach: This quantitative study design uses three hundred and seventy (370) sample units that were drawn from all levels in organizations in collecting data for the final analysis. Findings: Situational leadership style is the most dominant leadership style applied in global brand management. However, certain critical perspectives at the time of investigation revealed from the study are discussed in the paper. Originality/Value: This study is the first to provide underpinnings of employee's perception of leadership.
\end{abstract}

Keywords: Global Brand Management; Charismatic Leadership; Transactional Leadership; Transformational Leadership; Classical Leadership; Situational Leadership

\section{Introduction}

Many countries have benefited from globalization due to its immense use of information technology for the growth of international business. The World Trade Organization (WTO) has been of paramount importance in playing a key role in this exercise. The economic growth in BRIC (Brazil, Russia, India, and China) countries has been an eye-opener for many organizations in the world to channel their businesses in that direction. Especially, these BRIC countries have become the center of business attraction for many businesses due to their growing numbers of the economic demographic parameters. These growing economies have opened the business opportunities for many industries, hence, leaders in multinational organizations operating, especially in the United States are analyzing these economies for their lucrative business investment possibilities. However, one of the main criteria for global business success depends on the style of leadership applied in order to optimize the positive business outcome [1]. Moreover, leaders' guidance in maneuvering organizational resources in the appropriate direction has been a vital expectation of the stakeholders.
Therefore, the focus of this study is to investigate whether there is a specific leadership style applied compared to the leadership style perceived by the followers in multinational organizations operating in the United States that influences global brand management in achieving bottom-line expectations of the stakeholders.

\section{Literature Review}

There have been numerous seminal research conducted to publish study findings in the areas of leadership and brand management. Leadership is an organizational role that involves establishing and sharing the vision with the followers so that they will commit willingly, provide knowledge, create learning culture for continuous growth, commits to stakeholders' expectations [2]. According to Reference [3], a leader will influence his followers in order to achieve organizational goals in delivering the expectations of the stakeholders. Leaders have multifaceted skills in dealing with different business situations in order to find business solutions [3]. Leadership is one of the key concepts in discussion on the management platform painting different definitions from different per- 
spectives in today's business context. Domm [4] contends that leadership is a management quality that needs to be cultivated through an appropriate mentoring process in a right organizational climate that encourages it. On the contrary, Bass, [5], and Niranjan [6], argue that leadership is a management quality that embedded as an inborn temperament.

Many scholars have argued that charismatic leaders inspire followers through their inborn psychological temperaments [7-10]. However, the studies conducted so far had not been successful in establishing that the charismatic leadership affects the motivational theories [11]. "Charisma" which is "a gift" in Greek, has been frequently used in politics and religion to adduce legitimacy to power [11]. Bass [5] argues that it is an exceptional quality or power by virtue that sets apart one from the ordinary people. Hence, charismatic leadership can be defined as a skill or quality that one possesses in order to achieve positive individual and organizational outcomes by displaying behaviors that stimulate followers' needs [10]. According to Reference [12], the leader utilizes the "connectedness" to the followers in order to achieve congruence. In their discussion the key variables in the application of the leadership theory are envisioning, empathy, and empowerment. Choi [11], in his research findings argues that charismatic leadership style is the most commonly applied leadership style in many organizations in the United States. Further, he contends that charismatic leadership style is the most effective and mostly perceived leadership style in most of the multinational organizations in the United States.

Transformational leadership is also another key concept in discussion in academia giving many definitions based on the study conducted. Transformational leadership has always presented itself as a scientific theory backed up by numerous studies showing empirical evidence for its superiority over other forms of leadership [11]. Transformational leadership has been portrayed as a leadership process that creates an impact on the paradigm shift from individual goal achievement to organizational goal achievement [10]. The process of transformation is carried out by the leader based on the analysis of the employees' capabilities, level of motivation, prevailing organizational climate, future organizational goals, and other industry related implications [13]. In the application of this leadership theory, one exceptional theory discussed by Arbaugh, J. B. Arbaugh [14] stated that followers achieve more than what is expected from them.

Transactional leadership is a process where the leader implements a methodology to achieve goals beneficial to parties, leader and the follower $[15,16]$. They exchange the relationship between the leader and the follower to meet their own self-interests [13]. What is central to transactional leadership is that the parties within the ex- change relation do not fundamentally change their core values, level of motivation, and identity are stable. An example is a leader indicating a pay increment in relation to achievement of a target ("you do this, and you get this"). Michael [17] argues based on his research findings that transactional leadership is very much short term oriented rather than long term oriented. Some psychology experts argue that leaders possess certain traits that influence others who work as their followers [18-20]. These traits are assertiveness, the ability to motivate others and intelligence, which make them innate and great leaders [21]. However, some researchers argue that leader's behavior is subjective and depends on situation in hand $[22,23]$. This confirms the contingency theory presented in the arena of leadership [10]. The other theories related to classical leadership theories are discussed in the same literature review in order to explain the real world scenarios.

Grass [21] contends that all human relationships are formed by the subjective cost-benefit analysis and the comparison of all the alternatives confirming social exchange theory. In their argument they explain cost as anything that have negative value to a person while benefits are the positive values to a person. In most of the instances, the understanding of the both parties (leader and the follower) could end up with a dissonance [24]. The main reasons for this phenomenon are leader not being visionary, lack of congruence, lack of cohesiveness, and leader changing his or her leadership style to manage the situation in hand [10]. This argument confirms the cognitive dissonance theory. [2] explains that leaders have to understand the task in hand and apply their style of leadership depending on the situation dynamics. Therefore, leaders need to facilitate and motivate their followers to achieve organizational objectives with a commitment. This confirms the path-goal theory of leadership initially presented by Robert House in 1971 .

In the light of globalization, leaders have focused on building standard global brands for international terrains. This strategy has two benefits. First, the cost benefit that organization has in terms of managing standard global brands. Second, the benefit to the customers and consumers it offers in terms of easiness of brand awareness, recognition, recall, association, and repurchase [25]. However, this exercise is not a total responsibility of the leaders in organizations. The outcome of this exercise depends on a total team effort in the organization. Therefore, the responsibility of the leaders is to ensure that they set global brand vision, assign global brand management teams, communicate the global brand objectives, set the appropriate organizational climate, and appreciate the team efforts when achieved the global brand vision or the objectives [26]. Nevertheless, the managers of many organizations regardless of the size, business nature and 
the location, have confronted the challenges of comprehending what are teams, why teams are important especially in achieving a global brand leadership, and how team culture can be cultivated in order to foster better organizational results.

Leadership brands are built with adequate investments on effective team building, which could either build or ruin an organization. A brand could be a leader in the market place as long as it receives necessary nurturing from the organization [27]. This nurturing could be corporate climate, culture, technology, leadership, and systems. The requirement of effective teams has been a great challenge for most organizational leaders to maintain for the total business process effectiveness. This could not be achieved implementing only one team for the whole organizational performance [28]. Therefore, the necessity of teams to leverage mini systems and projects needed effective teams for comparatively superior performance. Under these mini projects, brand building is another project that needs effective teams to achieve global brand success.

In today's business context, a high degree of rivalry among competitors intensified the necessity of closely managing effective teams in order to create a high level of brand equity [29]. Close monitoring of the performance of the brands of these teams is needed owing to business influencing dynamics of the market place. These market dynamics are globalization, change of market structure, changing wants of consumers, and technological advancements [30]. These teams need to be self-managing, cultivating wisdom, engaging with the world, inspiring trust, setting mindset for continuous learning, crystallizing vision, developing expertise, and performance minded in building brand leadership for organizational success.

Brands need leadership in making their global identity effective. Leaders should identify the potential of the brand and set the grounds for the brands to perform extraordinary in assisting organizations to make above-average profits from respective markets [2]. Global brands would not be successful unless the leaders drive the brands in a direction to win the equity (consumer value and book value). The consumer aspect of the brand equity helps leaders in organizations to achieve a high level of brand awareness, association, and top of the mind, trial rate, and willingness to pay a premium price for the brand [31]. This needs a considerable amount of time spent on setting a vision for the brand, market analysis, industry analysis, and global analysis in detailed, designing, and implementing effective marketing programs locally and globally. Therefore, the leaders who understand the importance of brand management and set the groundwork for this drill are assets for organizations.

Leaders also depend on the brand's success in order to deliver the expectation of stakeholders. The successful brands will assist organizations directly or indirectly to achieve the organizational bottom lines. Brands with high equity will increase the book value of the organization for leaders to increase the share value that pays back the investors [25]. However, Altman [32] in his article argues that this endeavor (brand success in terms of equity) would not be possible without a team of highly committed followers who could assist the leaders to make the whole exercise possible. Hence, it is apparent that leadership and global brand management are codependent variables in the process of making an organization's success in achieving above-average profits.

\section{Methodology}

Specifically this study examines leadership styles; charismatic, transformational, transactional, or situational. Further, authors investigate the application and their disparities with the perception of the employees of the leadership styles applied in multinational organizations for their brand management. Related hypothesis developed in order to test are: 1) charismatic leadership style is the most commonly used leadership style in multinational organizations operating in the United States for their global brand success, 2) charismatic leadership style is the most effective leadership style when managing global brands for their brand success in multinational organizations, and 3) Charismatic leadership style is the mostly perceived leadership style by the followers (employees) in multinational organizations operating in the United States.

This study using a quantitative, non-experimental, correlation (explanatory) and (exploratory) cross-sectional survey research design examined the explanatory variables (global brand management and effective leadership) to determine, the style of leadership applied in multinational organizations operating in the United States for their global brand management. In addition, authors also pursued their investigation to understand any discrepancies between the application and perception of leadership styles by the followers (employees). Finally, grounded theories such as brand management and leadership were pursued.

Data was gathered from 60 multinational organizations from top 500 companies listed online in the year 2011 using a questionnaire (10 fast moving consumer goods, 20 financial service companies, 10 trading companies, and 20 IT companies) operating in the United States. The credibility of the sample frame (top 500 companies) is high as it represents successful business corporations that had employed qualified leaders and followers. The questionnaire was pre-tested for validity and reliability with a test survey conducted prior to the final implementation. Sample units are drawn from three strata and that are 
senior managers, functional managers, and operational staff in multinational organizations operating in the United States. The sample frame was designed in order to increase representation from variety of different industries. Finally, regression analysis and correlation were applied in quantifying the findings. This uses 370 completed surveys of which 340 were used for analysis.

\section{Results}

A total of 340 responses to examine leadership styles and brand management were used to analyze. The response rate was $91.89 \%$ which a satisfactory level according to the survey designed.

Correlation results between the influence of leadership and the effective global brand management is a negative correlation with a negative figure of -0.478 on a two-tail test performed (see Table 1). According to Pearson (2010) correlation analysis, it is statistically suggested that higher the influence of the leadership, lower the effectiveness of global brand management or it could also be visa verse. However, the table is not significant according to the rule for level of significance $(r=-0.47, p$ $>0.05$ ). Therefore, Table 1 establishes a negative correlation between the two variables, leadership styles and brand management.

Table 2 presents correlation between charismatic lead

Table 1. Correlation between leadership influence and global brand management.

\begin{tabular}{cccc}
\hline & & $\begin{array}{c}\text { Influence of } \\
\text { Leadership }\end{array}$ & $\begin{array}{c}\text { Effective Global } \\
\text { Brand Management }\end{array}$ \\
\hline $\begin{array}{c}\text { Influence of } \\
\text { Leadership }\end{array}$ & Searson Correlation & 1 & -0.478 \\
& Sig. (2-tailed) & & 0.522 \\
$\begin{array}{c}\text { Effective } \\
\text { Global Brand } \\
\text { Management }\end{array}$ & Sig. (2-tailed) & 0.522 & 4 \\
\hline & $\mathrm{N}$ & 4 & 1 \\
\hline
\end{tabular}

Table 2. Correlation between charismatic leadership and commonly used leadership style.

\begin{tabular}{|c|c|c|c|}
\hline & & $\begin{array}{c}\text { Charismatic } \\
\text { Leadership Style }\end{array}$ & $\begin{array}{l}\text { Commonly Used } \\
\text { Leadership Style }\end{array}$ \\
\hline \multirow{3}{*}{$\begin{array}{l}\text { Charismatic } \\
\text { Leadership Style }\end{array}$} & $\begin{array}{c}\text { Pearson } \\
\text { Correlation }\end{array}$ & 1 & -0.165 \\
\hline & Sig. (2-tailed) & & 0.487 \\
\hline & $\mathrm{N}$ & 20 & 20 \\
\hline \multirow{3}{*}{$\begin{array}{l}\text { Commonly Used } \\
\text { Leadership Style }\end{array}$} & $\begin{array}{c}\text { Pearson } \\
\text { Correlation }\end{array}$ & -0.165 & 1 \\
\hline & Sig. (2-tailed) & 0.487 & \\
\hline & $\mathrm{N}$ & 20 & 24 \\
\hline
\end{tabular}

ership style and commonly used leadership style statistics suggest as per the test performed under Pearson correlation two-tailed test, that there is a negative correlation between the variables in discussion. This negative correlation value is -0.16 . Therefore, it could be concluded based on statistics that there is a negative correlation between charismatic leadership and commonly used leadership style used in multinational organizations operating in the United States. One of the key inferences that could be drawn from the statistical analysis performed is that charismatic leadership style perceived by the followers would not be the commonly used leadership style or it could be vis-à-vis.

The data suggest that the most commonly used leadership style in multinational organizations operating in the United States is situational leadership style (delegating leadership style with recorded percentage of $29.13 \%$ followed by coaching $25.59 \%$, directing $22.89 \%$, and facilitating $22.38 \%$ ). Therefore, it nullifies the alternative hypothesis developed that charismatic leadership style that is commonly used leadership style in multinational organizations operating in the United States. Further, Table 3 shown below as a result of the regression analysis performed with predictive analysis using PASW statistical package (version 18) also establishes that charismatic leadership style (V1) influence the effective global brand management (V4).

As shown in Table 3, the $F$ ratio (0.41) and the low statistical significance $(0.58)$ values imply that the probability of the regression analysis output is with a high randomly performed minimizing the factual considerations. The above statistics further establishes that charismatic leadership style is not the commonly used leadership style used in multinational organizations operating in the United States; instead it is situational leadership style (delegating leadership style) that commonly used leadership style in the same industry.

Further, as a result of a regression analysis performed predictive analysis using PASW statistical package (version 18) also establish that charismatic leadership (V1) with a figure of 0.41 and the type of commonly used leadership style (V2) with a negative figure of -0.47 do not significantly influence the effective global brand ma-

Table 3. Regression analysis on charismatic leadership style and global brand management.

\begin{tabular}{|c|c|c|c|c|c|c|}
\hline \multicolumn{7}{|c|}{ ANOVA $^{b}$} \\
\hline \multirow{4}{*}{1} & Model & $\begin{array}{l}\text { Sum of } \\
\text { Squares }\end{array}$ & $\mathrm{df}$ & Mean Square & $F$ & Sig. \\
\hline & Regression & 2974288.16 & 1 & 2974288.16 & 0.415 & $0.585 \mathrm{a}$ \\
\hline & Residual & $1.43 \mathrm{E}+07$ & 2 & 7163793.42 & & \\
\hline & Total & $1.73 \mathrm{E}+07$ & 3 & & & \\
\hline
\end{tabular}


Table 4. Multi regression analysis on influence of charismatic leadership, management cultural factor consideration, and type of commonly used leadership style on effective global brand.

\begin{tabular}{|c|c|c|c|c|c|}
\hline & & $\begin{array}{l}\text { Effective Global Brand } \\
\text { Management (V4) }\end{array}$ & Charismatic Leadership (V1) & Situational Leadership (V3) & $\begin{array}{l}\text { Types of Commonly } \\
\text { Used Leadership (V2) }\end{array}$ \\
\hline \multirow{4}{*}{ Pearson Correlation } & VAR-4 & 1 & 0.415 & 0.152 & -0.478 \\
\hline & VAR-1 & 0.415 & 1 & 0.607 & 0.118 \\
\hline & VAR-3 & 0.152 & 0.607 & 1 & -0.501 \\
\hline & VAR-2 & -0.478 & 0.118 & -0.501 & 1 \\
\hline \multirow{4}{*}{ Sig. (1-tailed) } & VAR-4 & & 0.293 & 0.424 & 0.261 \\
\hline & VAR-1 & 0.293 & & 0.196 & 0.441 \\
\hline & VAR-3 & 0.424 & 0.196 & & 0.25 \\
\hline & VAR-2 & 0.261 & 0.441 & 0.25 & \\
\hline \multirow{4}{*}{$\mathrm{N}$} & VAR-4 & 4 & 4 & 4 & 4 \\
\hline & VAR-1 & 4 & 4 & 4 & 4 \\
\hline & VAR-3 & 4 & 4 & 4 & 4 \\
\hline & VAR-2 & 4 & 4 & 4 & 4 \\
\hline
\end{tabular}

nagement in multinational organizations operating in the United States.

Further, above table (Table 4) as a result of a multi regression analysis performed predictive analysis using PASW statistical package (version 18) also establish that charismatic leadership (V1) with a figure of 0.41 and the situational leadership (V3) with a figure of 0.15 significantly influence the effective global brand management which is treated as a constant variable in the multi regression analysis while type of commonly used leadership style (V2) with a negative figure of -0.47 does not significantly influence the effective global brand management in multinational consumer banks operating in the United States.

As per the above figure (Figure 1), the data suggest that over $72 \%$ from the total respondents responded that the perceived leadership style is effective or strongly effective. This confirms that situational leadership style is to be effective.

The above figure (Figure 2), explains the brand performance in percentages in relation to leadership styles applied and perceived between a periods of two to eight year. These brand performance parameters are, brand awareness (classical leadership 60\%, charismatic leadership 75\%, delegation leadership 100\%, coaching style $94 \%$, directing style $96 \%$, and facilitating style 95\%), top of the mind brand (classical style $70 \%$, charismatic style $40 \%$, delegation style $90 \%$, coaching style $87 \%$, directing style $76 \%$, and facilitating style $70 \%$ ), trial rate (classical style $20 \%$, charismatic style $17 \%$, delegation style $68 \%$, coaching style $70 \%$, directing style $63 \%$, and facilitating style 60\%), repeat purchases (classical style

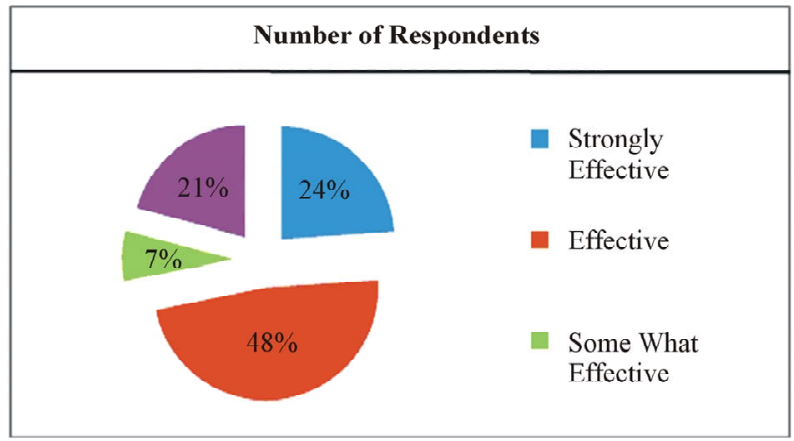

Figure 1. Effectiveness of perceived leadership style.

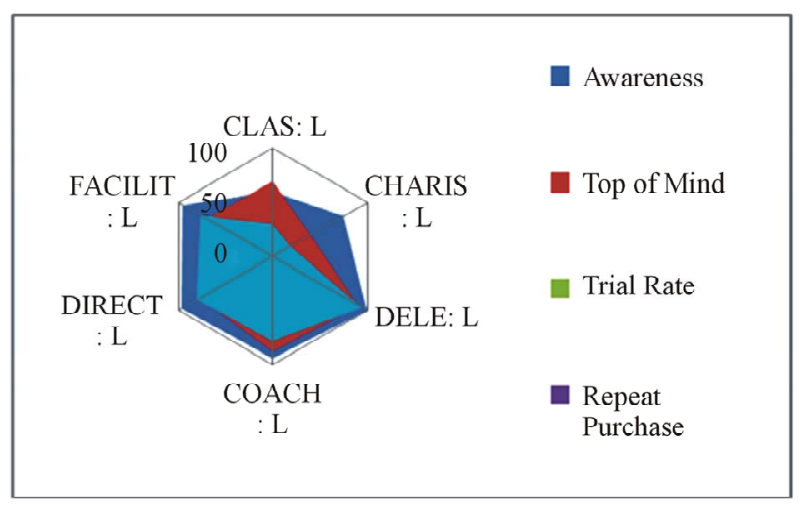

Figure 2. Leadership style and brand performances in percentage (between 2 - 8 year periods) leadership style and brand performances in percentage.

$10 \%$, charismatic style $9 \%$, delegation style $79 \%$, coaching style $68 \%$, directing style $65 \%$, and facilitating style $71 \%$ ), and brand association (classical style 30\%, char- 
ismatic style $19 \%$, delegation style $95 \%$, coaching style $79 \%$, directing style $80 \%$, and facilitating style $76 \%$ ). According to the above figure, it is apparent that during this period the application of the delegation leadership style yielded the highest level of global brand management proving the fact that it is the most applied leadership style in majority of the companies.

\section{Discussion}

The most commonly used leadership style in multinational organizations operating in the United States is situational leadership style (delegating leadership style followed by coaching, directing, and facilitating) in contrary to the most perceived leadership style which is charismatic leadership style used globally. This contradicts with the argument of $[6,17,21]$, in which they argue that charismatic leadership style is the most effective leadership style that is more congenial to human factors in organizations and these types of leaders induce the commitment of their followers using their charisma. Further, it is also established with statistics that the followers' perception of the leadership style which is the situational leadership style to be effective in global brand management.

Previous studies of leadership have concluded that there is no specific leadership style that could be applied in managing global brands in organizations. It is subjected to contextual specifications such as market size, potential, competition, potential market share, industry mechanism, demand, cultural aspects to demand, marketing capability of the organization, team dynamics, organizational structure, strategy, shared values, systems, and skills of the employees managing global brands $[28,30$, $31,33]$. The present study yields a very different portrait of leadership style establishing charismatic leadership style is the most commonly perceived leadership style while delegating leadership style as the most commonly used leadership style in the interest of the organizations operating in the United States based on the study.

\section{Limitations and Areas of Further Studies}

Authors identified certain areas of further research that needs to be conducted in search of real-world knowledge in this specific phenomenon which is application and perception of the leadership style. Additional research is needed on leadership for global brand management mismatch between most commonly perceived leadership style and commonly applied leadership style. As noted above in the discussion, it is impossible that this mismatch could be rectified through one study conducted. While there have been a few studies on this issue, there is no consistent evidence. Other two areas of investigation are plausible on factors affecting global brand manage- ment and a comprehensive investigation on all the variables that influence this entire phenomenon. Therefore, it is recommended that the influence of not only the mediating variables (effective leadership) but also of independent variable, which is effective global brand management on above-average returns for corporate growth, and survival need to be explored using a longitudinal study.

\section{Implications and Relevance to Business Industry}

Branding is one of the key areas that leaders have to manage efficiently in delivering stakeholder values through brand success. Efficient management of brands, especially in emerging economies accounts for application of effective leadership. Hence, the appropriate understanding of the application of the effective leadership style is of high importance in carrying out this exercise. Based on the study findings it is apparent that leaders of multinational and indigenous organizations operating in the United States could make use of a higher mileage in delivering stakeholder value through effective global brand management. Therefore, the findings of this paper could be of high importance to multinational organizations in order to understand how employees perceive their leaders' leadership style and to apply the most effective leadership style in order to reap the highest business yields in delivering stakeholder values through global brand management.

\section{REFERENCES}

[1] W. Turk, "Manager or leader?" Defense AT\&L, Vol. 36, No. 4, 2007, pp. 20-22.

[2] R. S. Bangari, "Leadership: A Critical Text," IMB Management Review, Vol. 21, No. 1, 2009, pp. 84-85.

[3] J. Napoli, "The Impact of Nonprofit Brand Orientation on Organizational Performance," Journal of Marketing Management, Vol. 22, No. 7-8, 2008, pp. 673-694. doi: $10.1362 / 026725706778612176$

[4] D. R. Domm, "Strategic Vision: Sustaining Employee Commitment," Business Strategy Review, Vol. 12, No. 4, 2006, p. 39. doi:10.1111/1467-8616.00191

[5] B. M. Bass, "From Transactional to Transformational Leadership: Learning to Share the Vision," Organizational Dynamics, Vol. 18, No. 3, 2006, pp. 19-31. doi:10.1016/0090-2616(90)90061-S

[6] E. A. Niranjan, "Global Branding Success," Journal of Marketing, Vol. 71, No. 3, 2008, pp. 132-167.

[7] S. Alden, "Leadership Qualities," Credit Union Directors Newsletter, Vol. 30, No. 12, 2006, p. 3-3.

[8] A. Zaleznik, "Managers and Leaders: Are They Different?" Harvard Business Review, Vol. 82, No. 1, 2007, pp. 74-81. 
[9] F. Small, "Leadership and International Strategy," Leadership Excellence, Vol. 11, No. 3, 2008, pp. 45-63.

[10] M. Z. Carter and A. Jones-Farmer, "Transformational Leadership and Followers' Performance: Joint Mediating Effects of Leader-Member Exchange and Interactional Justice," Academy of Management Proceedings, 2009, pp. 1-6.

[11] J. Choi, "A Motivational Theory of Charismatic Leadership: Envisioning, Empathy, and Empowerment," Journal of Leadership \& Organizational Studies (Baker College), Vol. 13, No. 1, 2006, pp. 24-43. doi:10.1177/10717919070130010501

[12] S. Spoelstra, "Transformational Leadership: Scientific Concept or Management Concept?" Academy of Management Proceedings, 2009, pp. 1-6.

[13] L. V. Gerstner Jr., "Leader vs. Executive," Across the Board, Vol. 40, No. 2, 2006, p. 10.

[14] J. B. Arbaugh, "Beyond Change Management: Advanced Strategies for Today's Transformational Leaders," Academy of Management Learning \& Education, Vol. 1, No. 2, 2006, pp. 221-223. doi:10.5465/AMLE.2002.8509421

[15] R. Vadivelu, "Leader and Culture," Journal of Management Studies, Vol. 21, No. 4, 2008, pp. 155-176.

[16] D. N. D. Hartog and J. J. Van Muijen, "Transactional versus Transformational Leadership: An Analysis of the MLQ," Journal of Occupational \& Organizational Psychology, Vol. 70, No. 1, 2007, pp. 19-34. doi:10.1111/j.2044-8325.1997.tb00628.x

[17] J. Michael, "Leader and Organizational Strategy," Greener Management International, Vol. 35, 2009, pp. 78-96.

[18] W. Bennis, "The Challenges of Leadership in the Modern World," American Psychologist, Vol. 62, No. 1, 2007, pp. 2-5. doi:10.1037/0003-066X.62.1.2

[19] V. Srinivasan and P. Chan-Su, "An Approach to the Measurement, Analysis, and Prediction of Brand Equity and Its Sources," Management Science, Vol. 51, No. 9, 2009, pp. 1433-1448. doi:10.1287/mnsc. 1050.0405

[20] S. Daniels, "Leadership Principles," Leadership Excellence, Vol. 22, No. 4, 2005, p. 10-10.

[21] M. Grass, "Charismatic Leadership," Journal of Manage- ment in Engineering, Vol. 25, No. 4, 2009, pp. 7-29.

[22] I. H. Buchen, "Paradigm-Shift Leadership," Leadership Excellence, Vol. 24, No. 7, 2007, pp. 19-20.

[23] J. Collins, "Aligning with Vision and Values," Leadership Excellence, Vol. 23, No. 4, 2006, p. 6-6.

[24] G. Christodoulides, "Breaking Free from the Industrial Age Paradigm of Branding," Journal of Brand Management, Vol. 15, No. 4, 2008, pp. 291-293. doi:10.1057/palgrave.bm.2550134

[25] J. J. Argo and M. C. Smith, "The Sounds of Brands," Journal of Marketing, Vol. 74, 2010, pp. 97-109. doi:10.1509/jmkg.74.4.97

[26] D. Ulrich and N. Smallwood, "Building a Leadership Brand," Harvard Business Review, Vol. 85, No. 7-8, 2007, pp. 92-100.

[27] V. U. Druskat and J. V. Wheeler, "Managing from the Boundary: The Effective Leadershipof Self-Managing Work Teams," Academy of Management Journal, Vol. 46, No. 4, 2009, pp. 435-457. doi:10.2307/30040637

[28] R. E. Kelley, "In Praise of Followers," Harvard Business Review, Vol. 66, No. 6, 2006, pp. 142-148.

[29] C. Mullally, "Leadership Brand," Leadership Excellence, 2008, p. 13-13.

[30] M. Javidan and P. W. Dorfman, "In the Eye of the Beholder: Cross Cultural Lessons in Leadership from Project GLOBE," Academy of Management Perspectives, Vol. 20, No. 1, 2006, pp. 67-90. doi:10.5465/AMP.2006.19873410

[31] B. J. Lewis, "Effective Team Leadership," Journal of Management in Engineering, Vol. 15, No. 3, 2008, p. 7.

[32] W. Altman, "Marketing in Rising Economies," Engineering \& Technology, Vol. 4, No. 11, 2009, pp. 76-77. doi:10.1049/et.2009.1120

[33] F. M. Morhart and W. Herzog, "Brand-Specific Leadership: Turning Employees into Brand Champions," Journal of Marketing, Vol. 73, No. 5, 2009, pp. 122-142. doi:10.1509/jmkg.73.5.122 